\title{
A Conceptual Model: The Impact of Sociodemographic on Coronary Heart Disease
}

\author{
Aza Azlina Md Kassim ${ }^{1}$, Juliza Mohamed ${ }^{2}$,Zainal Azhar Zainal Azim ${ }^{3}$, Mohamad Hafiz Rosli ${ }^{4}$ \\ Mohd Azrin Abd Rahim ${ }^{5}$ Mohd Nazil Salleh ${ }^{6}$ \\ ${ }^{1}$ Associate Professor, Faculty of Business and Accountancy, Universiti Selangor, Malaysia \\ 2,3,4,5 Lecturer, Faculty of Business and Accountancy, Universiti Selangor, Malaysia \\ ${ }^{6}$ Professor, PICOMS International University College, Malaysia
}

\begin{abstract}
:
The paper aims to examine the conceptual model on the impact of sociodemographic towards coronary heart disease. There is still limited study on the association between cost of living particularly the cost of food and housing and its impact on coronary heart disease. Therefore, this study incorporates five essential sociodemographic attributes namely, cost of food, children education cost, housing cost, smoking habit and gender. The study provides greater understanding on how the cost of living and lifestyle may give impact to coronary heart disease. It may provide the awareness among the regulators as the society faces burden of high cost of living. The burden may threaten the Malaysians quality of life particularly the lower income group.
\end{abstract}

Keywords: coronary heart disease, cost of food, children education cost, housing cost, smoking habit, gender

\section{Introduction}

The coronary heart disease is the leading cause of death worldwide, and it will continue to dominate future trends in global mortality. Stress level and unhealthy lifestyle are among the risk factors for heart disease. The stress derives from dealing with a higher cost of living. A new survey conducted by YouGov and Bayt.com has recently asked UAE residents about the major causes of stress in their lives. About 66 per cent said the increase in the cost of living contributed the most to stress levels (Maceda, 2017). As the coronary heart disease become more prevalent, it leads to a sharp rise in the health costs and reductions in quality of life. This paper discusses the conceptual model on the effect of financial distress, smoking habit and gender towards coronary heart disease.

\section{Literature Review \\ Coronary Heart Disease}

In the United States, one of every 6 deaths is caused by coronary heart disease (Cheng et al., 2019). China has shown serious concern towards the disease as the statistic indicates 11 million out of 290 million of its population have coronary heart disease ( $\mathrm{Li}$ et al., 2016). In Malaysia, heart disease has remained the principal cause of death among Malaysians in 2016. This constitutes to about $13.2 \%(21,410)$ of the total deaths in the country (Department of Statistics Malaysia, 2017).

The common symptoms among heart disease patients are pain, fatigue and breathlessness (Solano, Gomes \& Higginson, 2006). The factors that associate with the disease are high blood pressure, high blood glucose, overweight, high low-density lipoprotein cholesterol, less physical activity and males who smoke (Li et al., 2016). Stress might also be a risk factor for heart disease. The chronic stress exposes the body to unhealthy, persistently elevated levels of stress hormones like adrenalin and cortisol. Studies also link stress to changes in the way blood clots, which increases the risk of heart attack. The main common stressors that affect people at all stages of life is financial concern (Maceda, 2017). 


\section{Financial Distress}

Financial distress creates negative effects on one's health. The more stressed an individual become over his or her finances, the more irritable, anxious, worrisome he or she may become. The main factor which generates financial burden to an individual is due to higher costs of living that include cost of food, children education and housing.

\section{Cost of Food}

The cost of living is associated with the Consumer Price Index (CPI), which includes housing, transportation and food. CPI of the country has increased. The significant increases in costs are seen in the food and beverage (F\&B) sector (Hoo, 2018). Besides, between 2011 and 2015, food price inflation in Malaysia was 3.6 per cent on average, whereas overall inflation was 2.4 per cent over the same period (Hamid, 2017). It indicated a higher Food and Beverage Index as compared to overall inflation.

Among the factors that affect the food price in Malaysia are the increase in population where more than two million are immigrants, the changing of nutrition pattern and differing lifestyle had pushed up the demand for all food items. Among the low-income consumers, the demand is increasing for rice and daily food items such as fish, vegetables, chicken and fruits. The rise in food prices is also induced by the increase of inputs price such as fertilizers, labour, chemicals, machinery and land (Fatimah, 2018). However, the domestic food productions are not able to meet the demand for food even though the government has made an effort to increase the imported food (Fatimah, 2018). As a result, the food price increases as the supply is insufficient.

A report by Khazanah Research Institute's State of Households II in 2014 indicated that 94.6 per cent of households spent their money on food (Hamid, 2017). The increases in food price cause difficulties in the life of poor and low income households. They have to reduce available income for other expenses such as cost of transportation, education and parents' allowance. The households may also reduce their food consumption.

Increases in cost of living particularly the food price gives effect to individual or family behaviour (Chien \& Mistry, 2013) and stress (Ng, Yeung \& Gao, 2019; Maceda, 2017). The cost of living is unpredictable and uncontrollable. It creates stress as there is an imbalance between demand and the individual capacity to cope with such event. The stagnant or slow growth in disposable income and wages makes the scenario worse. The hard life leads them to have multiple jobs (Bouwhuis, Hoekstra, Bongers, Boot, Geuskens \& Van der Beek, 2019). The challenges in tight work schedules and various job responsibilities may contribute to stress (Bamberry \& Campbell, 2012). Besides, long working hours and less leisure time may give effect to health (Marucci-Wellman, Lombardi \& Willetts, 2016).

Continuous stress contributes to health problem (Holden, Harris, Hockey, Ferrai, Yong, Dobson \& Lee, 2019; Starrin, Aslund \& Nilsson, 2009; Skinner, Zautra \& Reich, 2004) including coronary heart disease (Buckland, Pozehl \& Yates, 2019). The coronary heart disease is known as the leading cause of death worldwide (Shu, et al., 2019). Thus, this study proposes that financial distress has significant effect on coronary heart disease.

\section{Children Education Cost}

Education nowadays is essential for everyone to pursue either the youth or adults in the aspects for human resource development (Karande \& Kulkarni, 2005). It also plays an important role of growing and developing a country's economic at the national level (Malaysia Education Blueprint, 2013). In attaining 'Wawasan 2020', the government of Malaysia had spent and invested lots of capital for education development. As reported in 2012, RM37 billion was allocated for education sector and that indicates the largest portion in its budget for that particular year. Thus, it shows that Malaysia put education as national priority in attaining the national goals (Malaysia Education Blueprint, 2013).

Public schools in Malaysia are governed by the Government of Malaysia and parents just need to pay an annual school fees and few miscellaneous fee. However, the cost of education is burdening for the low and middle-income families (Hassan \& Rasiah, 2011). Parents nowadays are striving to survive with the 
financial burden which includes the costs to be paid for children's education (Loh, 2004). First down payment, uniform cost, footwear expenses, additional kit expenses, high school expenses, additional private tuition expenses, foods and transport expenses are the costs a parent should bear when it comes to children's education (Loh, 2004). The costs were also mentioned in a study by Hassan and Rasiah, (2011). Similarly, Ahlstrom (2013) and Jenkner and Hillman (2005) noted that sending children to school is financially burdening to parents. Uniforms and books were reported to be the high costs and marked as intolerable load towards parents.

Financial burden has brought adults to the psychology effects that could harm the individual's health (Kementerian Kesihatan Malaysia, n.d). Since children's education cost is notified as a financial burden to parents, it might lead to health problem among the parents who struggle to bear the costs. An individual is likely to experience neither moderate nor severe stress which can trigger risk of heart disease if it gets prolonged (McEwen and Sapolsky, 2006). In addition, stress also could response to other heart problems such as obesity and damage on digestive system, immune system, and nervous system.

\section{Housing Cost}

Maslow's hierarchy of needs explains the needs of every human being in this world for a better living and one (1) of the basic things in the needs is physiological need which is shelter (Martin \& Joomis, 2007). A house acts as a shelter for the human being to be safe from any harm that might occur (Samaratunga, 2013). However, in this era, to own a property is not easy as the price of a house in Malaysia hike up every year (EdgeProp.my, 2018) and most of the household in Malaysia is rated as low and middle-income earners which have made difficult to them to own a property (Malay Mail, 2018). Since the income is stumpy, some of the adults have to rent a house instead of buying. In conjunction to the matter, low income earners are burdened by the rent cost (Goodman \& Ganesh, 2017). Hence, housing costs became a financial burden to the adults (Rowley, Ong \& Haffner, 2015).

Vidyattama, Tanton and Nepal (2013) noted that housing related financial stress is associated with income and housing costs-mortgage repayments and rents. Spending 30 percent from the income for the housing cost especially for the lower income earner can be categorized in housing stress (Yates, Randolph \& Holloway, 2006). Household debt service in Malaysia is a hot topic and worrying nowadays as it is affecting the young adults (Osman, Madzlan \& Ing, 2018). Thus, it doubles the problems for the young adults when it comes to bill payments. It also can lead to poverty when most of the earnings are spent for living. Mimura (2008) conducted a study which investigated the poverty between housing cost burden and economic hardship. The findings showed that the poverty status was not due to a housing cost burden instead of economic hardship. This explain, in the study, economic hardship among the groups (White, Black \& Hispanic) examined were different.

Little happen to be reported regarding the housing cost stress has significant relationship towards health problems. Jackson (2003) mentioned that housing is recognized as one of the main issues that influence human health. Nobari, Whaley, Blumenberg, Prelip and Wang (2019) in their study, reported that there was an association between housing cost burden and health. Children who lived in severe housing-cost burden have high chances to early childhood obesity and the size of the household was the moderator. When a person finds difficulty in settling house debt, he is experiencing housing stress. Housing stress can be defined as a situation where the household signify the negative effects when they have scarce income to assure sufficient housing cost (NAHP, 2004). Consequently, physical and emotional housing stress correlates to poor physical and mental health.

\section{Gender}

Increases in cost of living give effect to individual level of stress (Ng, Yeung \& Gao, 2019; Maceda, 2017). The stress responses among gender differences have become an essential issue which associated with various stressful life events. Previous studies have found significant association between stress and gender (Handa \& Chung, 2019). Gentry, Chung, Aung, Keller, Heinrich and Maddock (2007) found that there is no difference between health and social stress among genders. However, their study indicated that men have more stress from personal factors such as challenges or conflicts at workplace. The result may due to long period of time in paid employment among men (Victor, Bilodeau, Demers, Marchand, Beauregard, Durand \& Blanc, 2019). In contradict, Buckland, Pozehl and Yates (2019) found that females experienced more 
depression than men. Females with less education and no employment were related to high stress (Chang, Tan \& Schaffir, 2019).

With regards to health, World Heart Federation (2013) has reported that more females die of coronary heart disease than men in the US. Reasons being, female are more likely to have lack of physical fitness, hypertension and obesity. The World Heart Federation (2013)

also mentioned that female with obesity may increase by $64 \%$ of its risk to have heart disease, but only $46 \%$ in men. In addition, female who suffer heart disease at a younger age (less than 50 years old) have double risk to die as compared to men. It is also stated that the risk is higher for female; where $42 \%$ female with heart attack die within a year, but by only $24 \%$ in men.

Females have more responsibilities and higher sense of belonging to the family. They are willing to sacrifice for their loved ones. At the same time, they are accumulating the stress in themselves due to internal and external factors that they have to face including financial issue ( $\mathrm{Ng}$, Yeung \& Gao, 2019; Maceda, 2017). As a result, they tend to care less of their own health. It is found that, females with coronary heart disease tend to have less effective medical treatment, less education program enrolment and less prescription of diet (Chong-Nguyen, et al., 2019). It is assumed that, females experience more stress on the effect of insufficient financial resources (due to high cost of living) on health.

\section{Smoking Habit}

All tobacco products contain nicotine which have high addictive psychoactive ingredient. For smoking purposes, the dried leaves of tobacco are used in cigarettes, bidis, water pipe and cigar (Muhammad Zubair, 2019).

Smoking affects lungs and body immunity (Muhammad Zubair, 2019). Every year, tobacco kills more than 7 million people globally. More than 6 million of those deaths are caused by the direct tobacco use. The effect of being around people who are smoke is really bad. Around 890,000 deaths are the result of nonsmokers being exposed to secondhand smoke. The statistical shows that $80 \%$ of the world's 1.1 billion smokers are from low and middle income countries (World Health Organization, 2018). Smoking is identified as the important risk factor for heart disease (Wang et al., 2019; Kelishadi, Sadry, Zadegan, Hashemipour, Sabet, Bashardoust, Ansari \& Alikhassy, 2004).

There are various reasons that influence people to smoke. Preference for smoking among individuals whose parents (Kelishadi et al., 2004) and friends (Muhammad Zubair, 2019) are smoker were significantly more than other factors. Besides ages, number of smokers in the family and education level are considered as the contributing factors for an individual to take up smoking (Kelishadi et al., 2004). With regards to gender, the smoking habit is more dominant among males (Granja et al., 2019). Poor marital status and alcohol consumption also influence the smoking habits (Wang et al., 2019).

Individuals with high level of stress are more likely to smoke and difficult to quit (Bergman et al., 2019; Wang, et al., 2019). Stress resulting from work or studies is the determinants of smoking uptake (Wang et al., 2019). Besides, low socioeconomic status residents often face depression with the increases in cost of living. Unfavourable living conditions may increase their level of stress ( $\mathrm{Ng}$, Yeung \& Gao, 2019) and they are more likely to smoke (Hiscock, Bauld, Amos, Fidler \& Munafo, 2012). Those who smoke will feel that their emotions are under control or protect themselves from undesirable emotions including stress (Johnson et al., 2003). In turn, it develops a higher risk of heart disease (Wang et al., 2019).

Smoking habit is not only contributing to bad health, but the cost for buying cigarettes adding more expenses to an individual's cost of living (Hiscock et al. 2012). Thus, the habit will worsen the effect of increase in cost of living towards individual's health.

\section{Potential Contributions and Conclusion}

This study extends the coronary heart disease research. Prior studies have focused on the impact of education, cost of medication, physical activity, diabetes, cholesterol and hypertension on coronary heart disease (Moran, et al., 2019). However, there is still limited study on financial distress particularly on cost of living that associates with high cost of food and housing and its effect on the disease. A better understanding on how the cost of living and unhealthy lifestyle (smoking habits) contribute to coronary 
heart disease risks may provide input to the regulators in determining the minimum wage level and giving awareness on public health and financial management.

\section{References}

[1] Ahlstrom, D. (2013, April 21). School costs an 'unacceptable burden on parents'. Retrieved from https://www.irishtimes.com/news/education/school-costs-an-unacceptable-burden -on-parents1.1481250.

[2] Bamberry, L., \& Campbell, I. (2012) Multiple job holders in Australia: motives and personal impact. Aust Bull Labour, 38, 293-314.

[3] Bergman, H. E., Chan, P. K., Cooper, A., Shirley E., Goto, T., Fine, T., Cohen, G. H., Sampson, L., Ganocy, S., Tamburrino, M., Liberzon, I., Calabrese, J., Galea, S., \& Fenny, N. C. (2019). Examining the relationship between PTSD symptomatology and cigarette smoking among Ohio army national guard soldiers. Journal of Military Behavioral Health. DOI: 10.1080/21635781.2018.1556139.

[4] Bouwhuis, S., Hoekstra, T., Bongers, P. M., Boot, C. R. L., Geuskens, G. A., \& Van der Beek, A. J. (2019). Distinguishing groups and exploring health differences among multiple job holders aged 45 years and older. International Archives of Occupational and Environmental Health, 92(1), 6779.

[5] Buckland, A., S., Pozehl, B., \&Yates, B. (2019). Depressive symptoms in women with coronary heart disease: a systematic review of the longitudinal literature. Journal of Cardiovascular Nursing, 34(1), 52-59.

[6] Chang, M. W., Tan, A., \& Schaffir, J. (2019). Relationships between stress, demographics and dietary intake behaviours among low-income pregnant women with overweight or obesity. Public Health Nutrition, 22(6), 1066-1074 https://doi.org/10.1017/S13689 80018003385.

[7] Cheng, G., Chang, F., Wang, Y., You P., Chen, H., Han, W., Wang, J., Zhong, N., \& Min, Z. (2019). Factors influencing stent restenosis after percutaneous coronary intervention in patients with coronary heart disease: a clinical trial based on 1-year follow-up. Medical Science Monior, 25, 240247.

[8] Chien, N. C., \& Mistry, R. S. (2013). Geographic variations in cost of living: associations with family and child well-being. Child Development, 84(1), 209-225.

[9] Chong-Nguyen, C., Benedyga, V., Duchossoir, H., Issaurat , P., Berthelot, E., Barigou, A., Beauvais, F., Iliou, M. C., Bezard, M., Khabouri, M., Rouffiac, S., Peyrot, S., Thore, V., Bouleti, C., Henrion, C., Dias, S., Salvat, M., Bodez, D., Audureau, E., \& Damy, T. (2019). Do heart failure women and men have the same clinical characteristics and benefit from the same care management?: TIME'S UP!!! A report from the OFICSel Study. Archives of Cardiovascular Diseases Supplements, $11(1), 4$.

[10] Department of Statistics Malaysia. (2017). Statistics on causes of death, Malaysia, 2017. Retrieved from https://www.dosm.gov.my/v1.

[11] Fatimah, M. A. (2018, February 25). The rise in food prices: Why and what next. Retrieved from http://www.upm.edu.my/news/the_rise_in_food_prices_why_and_what_next-24964?L=en

[12] EdgeProp.my (2018). Median house price in Malaysia rise in 3Q18. Retrieved from https://www.theedgemarkets.com/article/median-house-price-malaysia-rises-3q18.

[13] Gentry, L. A., Chung, J. J., Aung, N., Keller, S., Heinrich, K. M., \& Maddock, J. E. (2007). Gender differences in stress and coping among adults living in Hawai' I. Californian Journal of Health Promotion, 5 (2), 89-102.

[14] Granja, G.L., Lacerda-Santos, J.T., Brilhante, D., Nobrega, I., Granville-Garcia, A. F., Caldas, A., \& Santos, J. A. (2019). Smoking and alcohol consumption among university students of the healthcare area. Journal of Public Heath, 1-8. DOI: 10.1007/s10389-018-01011-x

[15] Goodman, L., \& Ganesh, B. (2017). Low-income homeowners are as burdened by housing costs as renters. Retrieved from https://www.urban.org/urban-wire/low-income-homeowners-are-burdenedhousing-costs-renters. 
[16] Hamid, J. (2017, September 24). The economics of food prices. Retrieved from https://www.nst.com.my/opinion/columnists/2017/09/283364/economics-food-prices

[17] Handa, R. J., \& Chung, W. C. J. (2019). Stress: physiology, biochemistry, and pathology. Handbook of Stress Series, 3, 165-176.

[18] Hassan, O. R., \& Rasiah, R. (2011). Poverty and student performances in Malaysia. International Journal of Institutions and Economics, 3(1), 61-76.

[19] Hiscock, R., Bauld, L., Amos, A., Fidler, J.A., \& Munafo, M. (2012). Socioeconomic status and smoking: A review. Annals of the New York Academy of Sciences. 1248, 107-123.

[20] Holden, L., Harris, M., Hockey, R., Ferrari, A., Yong, Y. L., Dobson, A., \& Lee, C. (2019). Predictors of change in depressive symptoms over time: results from the Australian longitudinal study on women's health. Journal of Affective Disorders, 245, 771-778.

[21] Hoo, K. P. (2018, January 19). Food for thought on food prices. Retrieved from https://www.nst.com.my/opinion/letters/2018/01/326629/food-thought-food-prices.

[22] Johnson, J. L., Bottorff, J. L., Moffat, B., Ratner, P. A., Shoveller, J. A., \& Lovato, C. Y. (2003). Tobacco dependence: adolescents' perspectives on the need to smoke. Social Science \& Medicine, 56(7), 1481-1492. DOI: 10.1016/S0277-9536(02)00150-8

[23] Jackson, R. J. (2003). The impact of the built environment on health: An emerging field. American Journal of Public Health, 93(9), 1382-1384.

[24] Jenkner, E., \& Hillman, A. L. (2015). Educating children in poor countries. Economics Issues, 33.

[25] Karande, S., \& Kulkarni, M. (2005). Poor school performance. Indian Journal of Pediatrics, 72(11), 961-967.

[26] Kelishadi, R., Sadry, G., Zadegan, N. S., Hashemipour, M., Sabet, B., Bashardoust, N., Ansari, R., \& Alikhassy, H. (2004). Smoking, adolescents and health: Isfahan healthy heart programme-heart health promotion from childhood. Asia-Pacific Journal of Public Health, 16(1), 15-22.

[27] Kementerian Kesihatan Malaysia. (n.d). Kesan psikologi akibat masalah kewangan. Retrieved from http://www.myhealth.gov.my/kesan-psikologi-akibat-masalah-kewangan/.

[28] Li, Y., Wang, D. D., Ley, S. H., Howard, A. G., He, Y., Lu, Y., Danaei, G., \& Hu, F. B. (2016). Potential impact of time trend of life-style factors on cardiovascular disease burden in China. Journal of the American College of Cardiology, 68(8), 818-833.

[29] Maceda, C. (2017, January 15). Rise in living costs top cause of stress, but UAE residents 'satisfied' with life. Retrieved from http://gulfn ews.com/business/ economy/rise-in-living-costs-top-cause-ofstress-but-uae-residents-satisfied-with-life-1.1962099

[30] Loh, A. (2004). A young mum's school 'Balance Sheet' story: Parents struggle to cope with the financial burden of sending children to school. Aliran Monthly, 24, Issue 11/12.

[31] Malaysia Education Blueprint, M. (2013). Malaysia Education Blueprint 2013 - 2025. Retrieved from http://www.moe.gov.my

[32] Malay Mail (2018). Lower income group suffering from cost of living pressure, says World Bank. Retrieved from https://www.malaymail.com/news/money/2018/10/04/lower-income-groupsuffering-from-cost-of-living-pressure-says-world-bank/1679288.

[33] Marucci-Wellman, H. R., Lombardi, D. A., \& Willetts, J. L. (2016) Working multiple jobs over a day or a week: short-term effects on sleep duration. Chronobiol Int, 33, 1-20

[34] Moran, K. E., Ommerborn, M. J., Blackshear, C. T., Sims, M., \& Clark, C. R. (2019). Financial stress and risk of coronary heart disease in the Jackson heart study. American Journal of Preventive Medicine, 56(2), 224-231.

[35] Martin, D., \& Joomis, K. (2007). Building teachers: A constructivist approach to introducing education. Belmont, CA: Wadsworth.

[36] McEwen, B., \& Sapolsky, R. (2006). Stress and your health. The Journal of Clinical Endocrinology \& Metabolism, 91(2), E2.

[37] Mimura, Y. (2008). Housing cost burden, poverty status, and economic hardship among low-income families. Journal of Family and Economic Issues, 29, 152-16.

[38] Muhammad Zubair, T. (2019). Smoking and its risks in Saudi Arabia: Literature review. Hamdan Medical Journal. DOI: 10.4103/2227-2437.241549. 
[39] Ng, S. M., Yeung, C. H., \& Gao, S. (2019). A concise self-report scale can identify high expressed emotions and predict higher relapse risk in schizophrenia. Comprehensive Psychiatry, 89, 1-6.

[40] NAHP (2004). Housing affordability: a summary of evidence and issues in measurement, national affordable housing project. Report prepared for AHURI and Policy Research Working Group.

[41] Nobari, T. Z., Whaley, S. E., Blumenberg, E., Prelip, M. L., \& Wang, M. C. (2019). Severe housingcost burden and obesity among preschool-aged low-income children in Los Angeles County. Preventive Medicine Reports, 13, 139-145.

[42] Osman, Z., Madzlan, E. M., \& Ing, P. (2018). In pursuit of financial well-being: The effects of financial literacy, financial behaviour and financial stress on employees in Labuan. International Journal of Service Management and Sustainability, 3(1), 56-94.

[43] Rowley, S., Ong, R., \& Haffner, M. (2015). Bridging the gap between housing stress and financial stress: The case of Australia. Housing Studies, 30(3), 473-490.

[44] Samaratunga, T. (2013). High-density high- rise low-income housing: An appropriate city planning solution for Colombo, Sri Lanka (Thesis), Bond University.

[45] Shu, Z., Shar, A. H., Shahen, M., Wang, H., Alagawany, M., Abd El-Hack, M. E., Kalhoro, S. A., Rashid, M., \& Shar, P. A. (2019). Pharmacological uses of ginkgo biloba extracts for cardiovascular disease and coronary heart diseases. International Journal of Pharmacology, 15(1), 1-9.

[46] Skinner, M. A., Zautra, A. J. \& Reich, J. W. (2004). Financial stress predictors and the emotional and physical health of chronic pain patients. Cognitive Therapy and Research, 28(5), 695-713.

[47] Solano, J. P, Gomes, B., \& Higginson, I. J. (2006). A comparison of symptom prevalence in far advanced cancer, AIDS, heart disease, chronic obstructive pulmonary disease and renal disease. Journal of Pain and Symptom Management, 31(1), 58-69.

[48] Starrin, B., Aslund, C., \& Nilsson, K. W. (2009). Financial stress, shaming experiences and psychosocial ill-health: studies into the finances-shame model. Social Indicators Research, 91(2), 283-298.

[49] Victor, Y. H. III, Bilodeau, J., Demers, A., Marchand, A., Beauregard, N., Durand, P., \& Blanc, M. E. (2019). Sex, gender dynamics, differential exposure, and work-family conflict. Journal of Family Issues, 40(2), 215-239.

[50] Vidyattama, Y., Tanton, R., \& Nepal, B. (2013). The Effect of Transport Costs on Housing-related Financial Stress in Australia. Urban Studies, 50(9), 1779-1795. doi:10.1177/0042098012468342

[51] Wang, X., Zhang, T., Wu, J., Yin, S., Nan, X., Du, M., Liu, A., \& Wang, P. (2019). The association between socioeconomic status, smoking, and chronic disease in inner Mongolia in Northern China. International Journal of Environmental Research and Public Health, 16, 169.

[52] World Heart Federation (2013, July 29). Coronary artery disease continues to be neglected in women, despite it killing at least as many women as men. Retrieved from https://medicalxpress.com/news/2013-07-coronary-artery-disease-neglectedwomen.html?utm_source=TrendMD\&utm_medium=cpc\&utm_campaign=MedicalXpress_TrendMD -1

[53] World Health Organization (2018, March 9). Tobacco. Retrieved from https://www.who.int /newsroom/fact-sheets/ detail/tobacco

[54] Yates, J., Randolph, B., \& Holloway, D. (2006). Housing affordability, occupation and location in Australian cities and regions. Final Report No. 91, Australian Housing and Urban Research Institute, Melbourne. 